\title{
In situ Determination of K, Ca, S and Si in Fresh Sugar Cane Leaves by Handheld Energy Dispersive X-Ray Fluorescence Spectrometry
}

\author{
Marcelo B. B. Guerra, ${ }^{a, b}$ Andressa Adame, ${ }^{a}$ Eduardo de Almeida, ${ }^{a}$ Marcos A. S. Brasil, ${ }^{a}$ \\ Carlos E. G. R. Schaefer ${ }^{c}$ and Francisco J. Krug*,a
}

${ }^{a}$ Centro de Energia Nuclear na Agricultura, Universidade de São Paulo, Av. Centenário 303, 13416-000 Piracicaba-SP, Brazil

${ }^{b}$ School of Natural Sciences, Black Hills State University, 1200 University St., 57799 Spearfish, SD, USA

'Departamento de Solos, Universidade Federal de Viçosa, Av. Peter Henry Rolfs, 36570-900 Viçosa-MG, Brazil

\begin{abstract}
A portable energy dispersive X-ray fluorescence spectrometer was evaluated in the in situ analysis of fresh sugar cane leaves for real time plant nutrition diagnosis. Fresh leaf fragments ( $n=10$ sugar cane varieties; 20 fragments per leaf; 2 measurement sites per fragment) were irradiated and the averaged data from X-ray characteristic emission lines intensities (for $\mathrm{K}, \mathrm{Ca}$, $\mathrm{S}$ and $\mathrm{Si} \mathrm{K} \alpha$ lines) were in close agreement with mass fraction data obtained by a validated comparative method. The linear correlation coefficients (r) ranged from 0.9575 for Ca to 0.9851 for Si. The obtained limits of detection were at least two-fold lower than the critical nutrient levels. Manganese can also be properly determined, but validation still requires more robust calibration models. The proposed method is a straightforward approach towards the fast evaluation of the nutritional profile of plants avoiding time-consuming steps, which involve drying, grinding, weighing, and acid digestion.
\end{abstract}

Keywords: in situ analysis, portable X-ray fluorescence spectrometry, plant mineral analysis, sugar cane, silicon

\section{Introduction}

Plant nutrition diagnosis is a well-established and reliable way for guiding the proper fertilizer recommendation contributing to the healthy growing of crops of economic importance. ${ }^{1}$ The analytical protocol most frequently applied for the determination of macro- and micronutrients in plant materials often requires an a priori test sample decomposition, usually performed by microwave-assisted acid sample dissolution, followed by determination using inductively coupled plasma optical emission spectrometry (ICP OES). ${ }^{2}$

Some studies have focused on the use of the direct solid sampling analysis based on X-ray fluorescence spectrometry $(\mathrm{XRF}),{ }^{3-5}$ laser-induced breakdown spectroscopy (LIBS) ${ }^{6-8}$ or laser ablation inductively coupled plasma mass

*e-mail: fjkrug@cena.usp.br

This paper is part of the PubliSBQ Special Issue "IUPAC-2017" (http://publi.sbq.org.br/). spectrometry (LA-ICP-MS) ${ }^{9-11}$ for assessing the mineral nutrition profile of plants. The most common way of sample presentation by using the aforementioned direct analysis methods involves the interrogation of a previously ground plant material in a pellet form. ${ }^{6,9}$ A promising trend of research is the direct analysis of the dried plant leaf without the need for grinding or pelletizing steps. ${ }^{12}$ On this subject, both LIBS and energy dispersive XRF (EDXRF) have been used.

The increasing advances in the field of portable instrumentation has expanded the application of this emerging technology. Such a fast development is due to improvements in digital electronics and in the development of miniaturized sensors and other crucial components. These novel mobile equipment offer a plethora of advantages to the analyst such as real time and onsite determinations of organic and inorganic analytes in a myriad of sample matrices. ${ }^{13-15}$ In case of the use of portable LIBS and EDXRF systems, the most common 
in situ applications involve the determination of potentially toxic metals in soil, ${ }^{16-19}$ and analysis of samples as diverse as those of industrial, geological, archaeological and of cultural heritage interest. ${ }^{18,20-25}$

The appropriate analytical performance exhibited by commercially available portable XRF instruments have been recently demonstrated elsewhere ${ }^{5,26}$ and certainly contributed to spark the interest of researchers in the proposition of in situ methods using such a mobile instrumentation. Particularly, the use of portable XRF (PXRF) systems in the determination of macro- and micronutrients in plant materials has received increased attention by the scientific community. ${ }^{5,27-30}$

The applicability of PXRF for total element determination, including macro-, micronutrients and the beneficial element ( $\mathrm{Si}$ ), was first demonstrated by McLaren et al..$^{29}$ when analyzing corn, cotton, soybean and wheat materials. Test portions $(2.0 \mathrm{~g})$ composed of ground plant samples were weighed into cylindrical plastic containers and then sealed with a 76 by $40 \mathrm{~mm}$ rectangular sheet of $1.5 \mu \mathrm{m}$ thick Mylar X-ray polyethylene film properly secured with a $20 \mathrm{~mm}$ rubber band. For minimizing air attenuation and for increasing PXRF sensitivity, the window covering the detector was removed, and helium gas was injected through the vacuum nipple. Measurement (scanning) times varied from as low as $120 \mathrm{~s}$ for corn and wheat to as high as $420 \mathrm{~s}$ for soybean test samples. For corn, cotton, and soybean, significant linear correlations were observed between the mass fractions data obtained by ICP OES and the PXRF measurements for Ca, $\mathrm{Co}, \mathrm{Cr}, \mathrm{Fe}, \mathrm{K}, \mathrm{Mn}, \mathrm{Ni}, \mathrm{P}, \mathrm{S}, \mathrm{Si}$, and $\mathrm{Zn}$.

Reidinger et al..$^{28}$ determined silicon and phosphorus in pelletized materials from ground leaves of three plant species of the Poaceae family (Deschampsia cespitosa, Lolium perenne and Triticum aestivum) by PXRF. Analyses were conducted with $6.2 \mathrm{kV}$ and $10 \mu \mathrm{A}$ using $8 \mathrm{~mm}$ X-ray spot size. The analytical throughput of the proposed method achieved 200 test samples per day, including the time required for pellet preparation of previously ground materials and the measurement itself.

Guerra et al..$^{5}$ compared the analytical performance of benchtop and handheld EDXRF systems for the direct determination of $\mathrm{P}, \mathrm{K}, \mathrm{Ca}, \mathrm{S}, \mathrm{Fe}, \mathrm{Mn}$, and $\mathrm{Si}$ in pellets of cryogenically ground sugar cane leaves ( $n=23$ varieties). Both systems exhibited similar limits of detection (LOD) for all analytes of interest, fitting for the intended purpose of evaluating the mineral nutritional status of sugar cane crop. Authors conclude that the handheld system is a cost-effective and appealing alternative for those interested in the in situ and laboratory analysis with equivalent performance of the benchtop unit.
Tighe and Forster ${ }^{27}$ used a PXRF system to determine the elemental content of plant litter samples collected from underneath perennial woody vegetation. Ground test samples were analyzed, and best results in terms of linearity were attained for $\mathrm{Ca}$ and $\mathrm{K}$ thanks to their higher mass fractions (as high as $4 \% \mathrm{~m} \mathrm{~m}^{-1} \mathrm{Ca}$ ), and their higher atomic numbers compared to other elements.

Most recently, Towett et al..$^{30}$ investigated several ways of sample presentation for analysis by PXRF of previously ground plant materials. The following analytical strategies were evaluated: $(i)$ direct sample surface analysis under vacuum; (ii) use of an XRF sample cup sealed by a Prolene ${ }^{\circledR}$ thin-film window; (iii) analysis under atmospheric pressure. Authors concluded that the direct sample measurements under vacuum are essential conditions for obtaining accurate data, especially for the low-atomic number elements. Another important conclusion depicted in this study is that accuracy and sensitivity are not only dependent on the selected operating conditions, but also on the choice of equipment's brand and model.

To the best of the authors' knowledge, there is just one study on the in situ foliar analysis by PXRF. In this investigation, ${ }^{31}$ handheld XRF scans were performed on fresh corn leaves obtained from plants grown on soils treated with phosphorus fertilizer from mineral sources or manure-amended. Good correlation $\left(\mathrm{r}^{2}\right.$ as high as 0.918) was observed between the $\mathrm{P} K \alpha$ emission line intensities (normalized by the Ag L $\alpha$ scattered line) and the corresponding $\mathrm{P}$ mass fractions.

In the present study, it is evaluated the feasibility of the in situ analysis of fresh leaves of sugar cane, an important cash crop of the tropical regions, aiming at nutrition diagnosis using a portable, handheld EDXRF equipment.

\section{Experimental}

\section{Handheld instrumentation}

The handheld EDXRF equipment used for the in situ analysis of fresh sugar cane leaves was the compact Tracer III-SD model (Bruker AXS, Madison, USA), furnished with a Rh target X-ray tube and a $10 \mathrm{~mm}^{2} \mathrm{X}$-Flash ${ }^{\circledR}$ Peltiercooled silicon drift detector (SDD) with 2048 channels. The instrument is equipped with a portable battery-operated vacuum pump to achieve pressures lower than 5 torr, which is an especially important condition for the detection of lowatomic number elements, such as silicon and sulfur. An acrylic stand and a metal enclosure radiation shield from the same manufacturer were also used. Bruker Spectra Artax software (Bruker Nano GmbH, Berlin, Germany), version 7.4.0.0, was used for providing the net counts per X-ray emission line. 
Evaluation of measurement time for the analysis of fresh sugar cane leaves by handheld EDXRF

Seven measurement times (10, 50, 100, 150, 200, 250, and $300 \mathrm{~s}$ ) were evaluated by using the handheld EDXRF spectrometer in order to obtain a compromise condition between measurement precision (lower coefficients of variation) and sampling throughput. For this purpose, a sugar cane plant (CTC 04 variety) was removed from the experimental field, transplanted into a pot containing soil, and brought to the laboratory. The top visible dewlap (TVD) leaf was selected, washed with deionized water, and superficially dried with a clean paper towel. A randomly chosen sampling site in the middle-third portion of the previously cleaned TVD leaf was analyzed in quintuplicate for each measurement time.

\section{In situ analysis}

In situ analysis were performed in the experimental field of the Centro de Tecnologia Canavieira located in Piracicaba, São Paulo State, Brazil. The following sugar cane varieties were selected: CTC 01, CTC 02, CTC 04, CTC 05, CTC 09, CTC 12, CTC 17, CTC 20, CTC 9001, and SP-832847. The handheld EDXRF spectrometer and the vacuum pump were connected to a $12 \mathrm{~V}$ car battery using a $400 \mathrm{~W}$ voltage inverter (Rally Manufacturing, Miami, USA). To ensure continuity of work and charged battery, the vehicle was put into operation for 15 min every 90 min experimental activity. In each of the 10 sugar cane varieties, the TVD leaf was selected and the final third portion of this diagnostic leaf was discarded prior to the start of analysis. The middle-third portion of the TVD leaf was sequentially fractionated in 20 equally spaced fragments (with ca. $2 \mathrm{~cm}$ in length and approximately $4 \mathrm{~cm}$ wide). Only the fragment to be immediately irradiated was removed from the plant, being previously thoroughly washed with deionized water, and superficially dried with a clean paper towel right before analysis. A semi-analytical balance connected to the battery was used to weigh the leaf fragment before and after analysis. The previously cleaned and weighed leaf fragments were directly analyzed in their upper surfaces at two sampling sites diametrically opposed to the leaf midrib for $50 \mathrm{~s}$. This sampling strategy was based on the recommendations of a study ${ }^{12}$ carried out with dried sugar cane leaves in a benchtop EDXRF system.

A schematic overview of the proposed protocol for the in situ analysis of fresh sugar cane leaves is shown in Figure 1. The operating conditions selected for the in situ analysis by using the handheld EDXRF system were: $40 \mathrm{kV}$ $\mathrm{X}$-ray tube voltage, $12 \mu \mathrm{A}$ tube current, $50 \mathrm{~s}$ irradiation time, and spectral region from 1 to $40 \mathrm{keV}$. The scattering radiation method based on the use of the $\mathrm{Rh} \mathrm{K} \alpha$ Compton peak $^{3}$ was employed for checking and correcting potential matrix effects in the analysis of fresh sugar cane leaves.

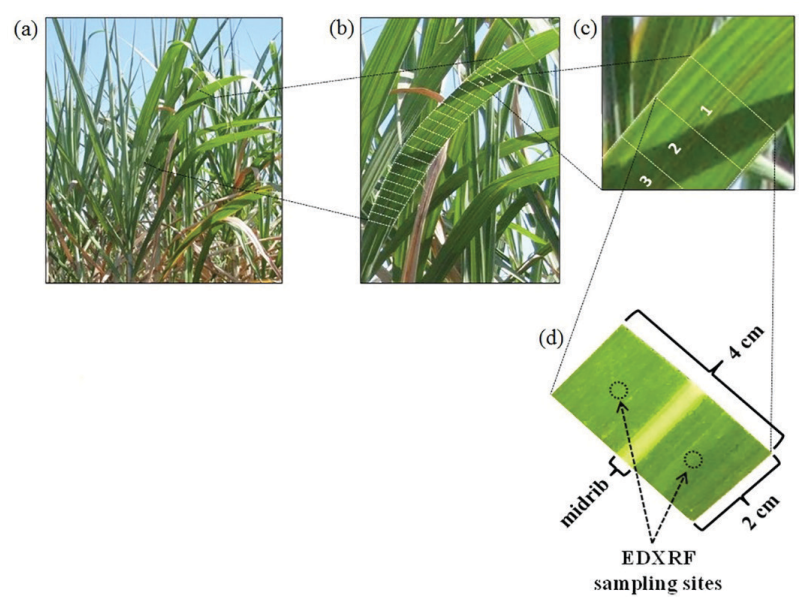

Figure 1. Schematic diagram of the proposed in situ method of analysis of fresh sugar cane leaves by handheld EDXRF. (a) Identification of the middle third portion of the top visible dewlap (TVD) leaf; (b) selection of the test samples and cutting of each leaf fragment $(n=20)$ sequentially at the time of analysis; (c) the cut leaf fragment is cleaned with deionized water, superficially dried, and weighed right before analysis; (d) direct analysis of the leaf fragment by PXRF. Operating conditions: $50 \mathrm{~s}$ irradiation time per site $(n=20$ fragments per diagnostic leaf, and 2 measurement points per leaf fragment); $40 \mathrm{kV} \mathrm{X-ray} \mathrm{tube} \mathrm{voltage;} 12 \mu \mathrm{A}$ $\mathrm{X}$-ray tube current; analysis under vacuum (below 5 torr).

\section{Comparative method for elemental mass fractions} determination

After the in situ analysis, all leaf fragments from each sugar cane variety were transported to the laboratory and oven-dried at $60{ }^{\circ} \mathrm{C}$ until constant weight. Each dried leaf fragment was weighed for determining the moisture content. The midrib was removed and the leaf fragments ( $n=20)$ were cryogenically ground (6875 Freezer/ Mill®, Spex, Metuchen, NJ, USA) for 30 min to obtain a homogeneous sample, which holds the average elemental mass fractions of all analyzed leaf fragments.

Pellets were prepared by transferring $0.5 \mathrm{~g}$ of powdered material to a cylindrical stainless steel die set $(15 \mathrm{~mm}$ internal diameter) followed by application of $8 \mathrm{t} \mathrm{cm}^{-2}$ for $3 \mathrm{~min}$. The obtained pellets were ca. $2 \mathrm{~mm}$ thick.

The pelletized test samples $(n=10)$ were analyzed with a benchtop EDXRF instrument (EDX720, Shimadzu, Kyoto, Japan) using a validated method for sugar cane leaves. ${ }^{5}$ In this comparative method, pellets obtained from the ground leaves of 23 sugar cane varieties (CTC1 to CTC18, IAC 85-5433, RB 86-7515, IAC 87-3396, IAC 93-6006, and IAC 81-3250) were used for calibration, their elemental mass fractions being previously determined by ICP OES 
after microwave-assisted acid digestion. The known mass fractions were used as comparative values to build the handheld EDXRF calibration models for P, K, Ca, S, Mn and $\mathrm{Si}$ with the corresponding X-ray characteristic emission lines intensities from the in situ analysis. The error estimation was evaluated by calculating the root mean square error of prediction (RMSEP) as described elsewhere. ${ }^{5}$

Limits of detection

Background (BG) data for K, Ca, S, Mn and Si K $\alpha$ peaks were calculated by the equipment software from the spectra obtained by 10 randomly chosen measurements from 10 different fresh sugar cane leaves. LODs were calculated according to IUPAC recommendation ${ }^{32}$ by applying the following expression: $3.3 \frac{\mathrm{s}}{\mathrm{b}}$, where $\mathrm{s}$ is the estimated standard deviation from the BG intensities, and $\mathrm{b}$ is the slope of the analytical curve.

\section{Results and Discussion}

\section{Preliminary in situ screening}

The initial evaluation of handheld EDXRF for the in situ analysis of fresh plant leaves was conducted by a qualitative screening in several sugar cane varieties in order to provide insights for the subsequent quantitative analysis. In this preliminary step, it was possible to detect four macronutrients ( $\mathrm{P}, \mathrm{K}, \mathrm{Ca}$, and $\mathrm{S}$ ), one micronutrient (Mn), and a beneficial element $(\mathrm{Si})$ in the averaged spectrum obtained from 40 measurements made in the middle-third portion of the diagnostic leaf from the CTC 5 variety (Figure 2), where the following X-ray emission lines are highlighted: $\mathrm{Si} \alpha \alpha 1.74 \mathrm{keV}, \mathrm{P} \mathrm{K} \alpha 2.01 \mathrm{keV}, \mathrm{S} \mathrm{K} \alpha 2.31 \mathrm{keV}$, $\mathrm{K} \mathrm{K} \alpha 3.31 \mathrm{keV}, \mathrm{Ca} \mathrm{K} \alpha 3.69 \mathrm{keV}$, Ca K $\beta 4.01 \mathrm{keV}$, and $\mathrm{Mn} \mathrm{K} \alpha 5.90 \mathrm{keV}$. The mass fractions of the corresponding elements in this diagnostic leaf, which were determined by the comparative method described herein, were $6.50 \pm 0.04 \mathrm{~g} \mathrm{~kg}^{-1} \mathrm{Si}, 1.73 \pm 0.02 \mathrm{~g} \mathrm{~kg}^{-1} \mathrm{P}, 2.11 \pm 0.03 \mathrm{~g} \mathrm{~kg}^{-1} \mathrm{~S}$, $11.17 \pm 0.08 \mathrm{~g} \mathrm{~kg}^{-1} \mathrm{~K}, 3.65 \pm 0.04 \mathrm{~g} \mathrm{~kg}^{-1} \mathrm{Ca}$, and $100 \pm 3 \mathrm{mg} \mathrm{kg}^{-1} \mathrm{Mn}$. Based on these preliminary findings, the aforementioned elements were considered potential analytes for further systematic studies.

\section{Evaluation of handheld EDXRF measurement times for the in situ analysis of fresh sugar cane leaves}

Handheld EDXRF measurement times were evaluated between 10 and $300 \mathrm{~s}$, and the coefficients of variation (CV) varied from as low as $0.33 \%$ for $\mathrm{Ca}$ at $250 \mathrm{~s}$ to as

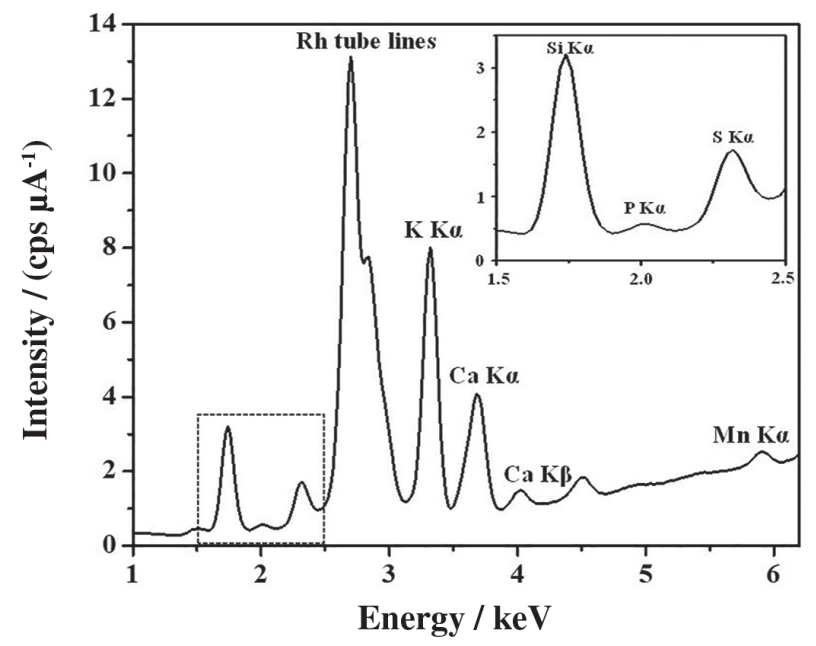

Figure 2. Fragment of EDXRF spectrum highlighting $\mathrm{Si} \mathrm{K} \alpha, \mathrm{P} \mathrm{K} \alpha, \mathrm{S} \mathrm{K} \alpha$, $\mathrm{K} \mathrm{K} \alpha, \mathrm{Ca} \alpha, \mathrm{Ca} \mathrm{K} \beta$, and $\mathrm{Mn} \mathrm{K} \alpha$ peaks obtained from the in situ analysis of the middle-third portion of a fresh sugar cane diagnostic leaf from CTC 05 variety; average spectrum from $n=40$ measurements (20 fragments, 2 measurements per fragment) by the handheld spectrometer. Elemental mass fraction data: $6.50 \mathrm{~g} \mathrm{~kg}^{-1} \mathrm{Si}, 1.73 \mathrm{~g} \mathrm{~kg}^{-1} \mathrm{P}, 2.11 \mathrm{~g} \mathrm{~kg}^{-1} \mathrm{~S}, 11.17 \mathrm{~g} \mathrm{~kg}^{-1} \mathrm{~K}$, $3.65 \mathrm{~g} \mathrm{~kg}^{-1} \mathrm{Ca}$, and $100 \mathrm{mg} \mathrm{kg}^{-1} \mathrm{Mn}$.

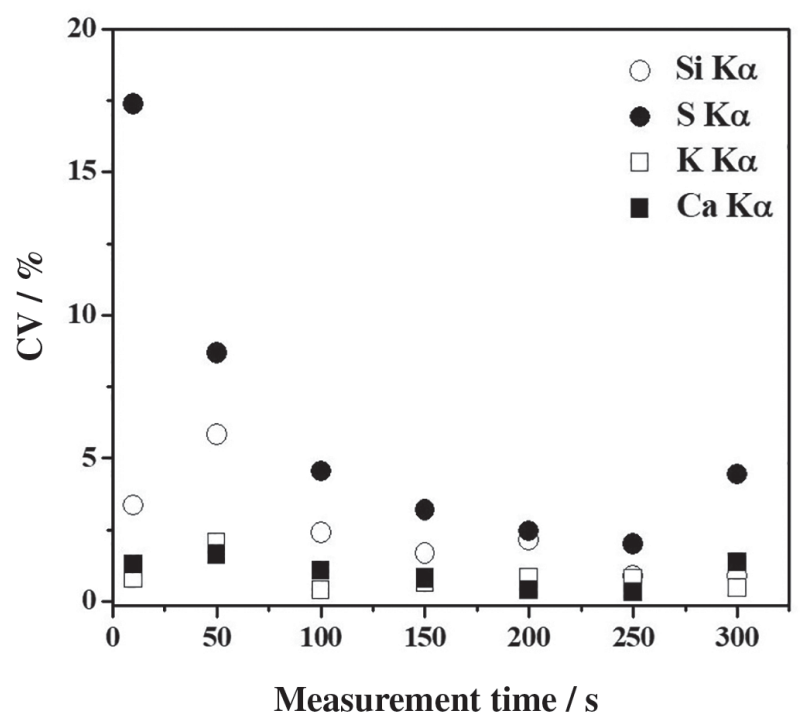

Figure 3. Influence of the irradiation time in the measurement precision for the direct analysis of a fresh sugar cane leaf by handheld EDXRF. Coefficients of variation (CV) based on five replicate measurements in a randomly chosen sampling site from the middle-third portion of the diagnostic leaf. Monitored X-ray peaks: $\mathrm{Si} \alpha \alpha 1.74 \mathrm{keV}, \mathrm{S} \mathrm{K} \alpha 2.31 \mathrm{keV}$, $\mathrm{K} \mathrm{K} \alpha 3.31 \mathrm{keV}$, and $\mathrm{Ca} \mathrm{K} \alpha 3.69 \mathrm{keV}$.

high as $17 \%$ for $\mathrm{S}$ at $10 \mathrm{~s}$ (Figure 3). The selection of $50 \mathrm{~s}$ irradiation time is an appropriate option for obtaining both high sampling throughput and adequate measurement precision $(\mathrm{CV}<10 \%$ for all tested analytes, $\mathrm{n}=5)$.

In situ analysis

The mean moisture loss during the in situ analysis for 
the fresh leaf fragments was $1.8 \%$, and the total moisture content of these analyzed test samples varied from $65 \pm 4$ to $74 \pm 2 \% \mathrm{~m} \mathrm{~m}^{-1}$.

Averaged data from X-ray characteristic emission lines intensities (for $\mathrm{Si}, \mathrm{S}, \mathrm{K}$, and $\mathrm{Ca} \mathrm{K} \alpha$ lines) from the analysis of fresh leaf fragments of sugar cane were in close agreement with mass fraction data of a whole diagnostic leaf on a dry matter basis obtained with a validated comparative method. The linear correlations are shown in Figure 4. The X-ray data uncertainties were not provided because each reported result was obtained from the average of 40 measurements in 20 leaf fragments, which are not authentic replicates. The linear correlation coefficients (r) ranged from 0.9575 for $\mathrm{Ca}$ to 0.9851 for Si. In Supplementary Information (Figure S1), linear correlation for Mn was also provided. Notwithstanding, the
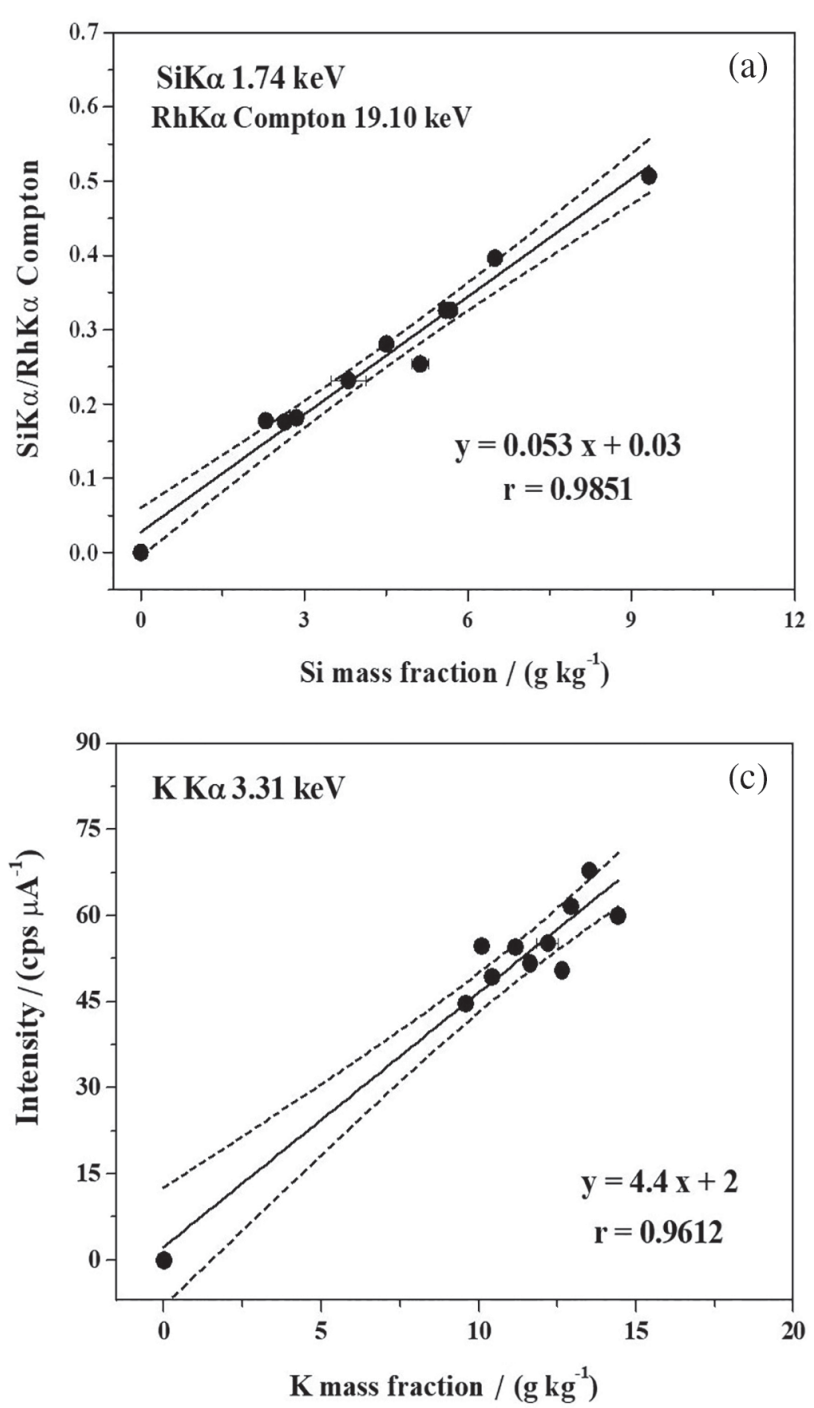

obtained calibration model for this element was not robust enough given the low variation in Mn mass fractions in the calibration pellets and its high estimated limit of detection.

The use of the Rh K $\alpha$ Compton peak for correcting potential matrix effects was effective for improving the linear correlation coefficients for both $\mathrm{Si}$ and $\mathrm{Mn}$ analytical curves (Figures $4 \mathrm{a}$ and S1, respectively). However, no significant improvements were observed for $\mathrm{K}, \mathrm{Ca}$, and $\mathrm{S}$.

In Table 1, the analytical figures of merit (LOD and RMSEP) from the analysis of fresh sugar cane leaves and pellets of cryogenically ground sugar cane leaves are shown. These data were obtained with the same handheld EDXRF instrument by using similar operating conditions: X-ray tube voltage (40 keV) and X-ray tube current $(12 \mu \mathrm{A})$. The only difference was related to the measurement time, which was $150 \mathrm{~s}$ for pellet interrogation
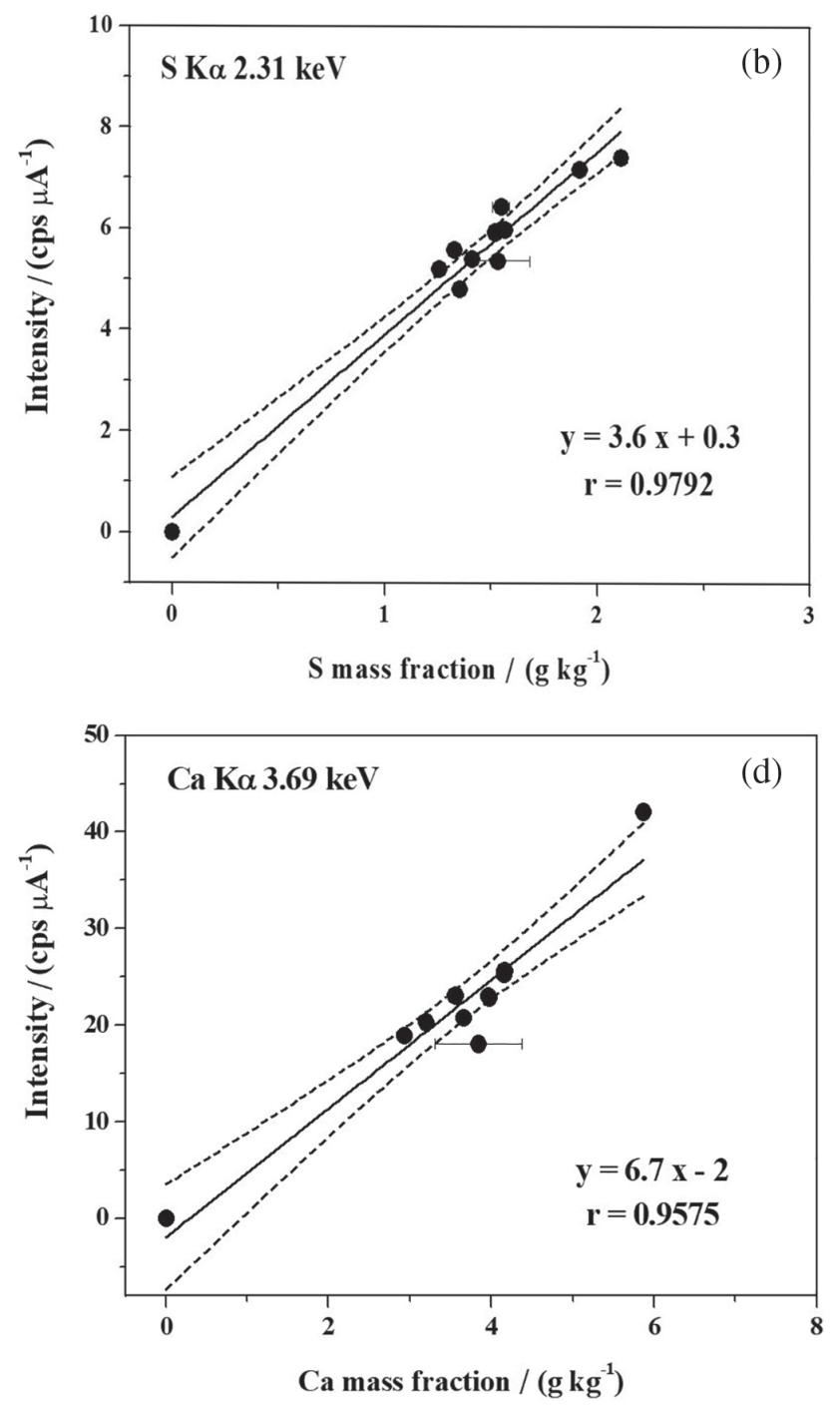

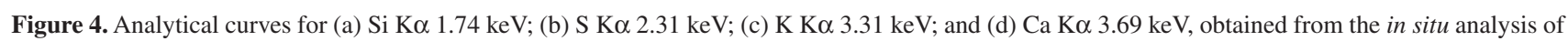
fresh sugar cane leaves by a handheld EDXRF spectrometer. The Si K $\alpha$ emission line intensities were corrected by the scattering radiation method using the Rh K $\alpha$ Compton peak at $19.10 \mathrm{keV}$. Dotted lines represent $95 \%$ confidence bands. 
and $50 \mathrm{~s}$ for in situ analysis of fresh leaves. In general, better figures of merit were obtained when presenting the test sample for analysis pressed in a pellet, with the only exception for silicon, whose LOD was lower for the in situ analysis of fresh leaves. A possible explanation for this behavior is that plants from the Poaceae family (e.g. rice, maize, wheat, sugar cane) accumulates silica as a $2.5 \mu \mathrm{m}$ layer immediately beneath the leaf cuticle. ${ }^{33}$ Then, a higher sensitivity is expected for silicon when analysis is performed in the unground leaf test sample. The predictive power of the calibration models was evaluated by the calculation of RMSEP. The lower RMSEP the higher the predictive capability of the calibration models. The obtained RMSEP data can be considered appropriate, since they were of the same order of magnitude of the calculated limits of detection (Table 1).

The estimated limits of detection for the in situ determination of $\mathrm{Si}, \mathrm{S}, \mathrm{K}$, and $\mathrm{Ca}$ can be considered suitable for the foliar diagnosis of sugar cane, as they are at least two-fold lower than their recommended critical levels (Table 1). The critical nutrient level is the threshold below which the element under consideration can be a limiting agent for the crop production. ${ }^{34}$

The proposition of an in situ method for quantitative determination of silicon in fresh sugar cane leaves is of particular relevance, since this agricultural crop absorbs more silicon from the soil than any other mineral nutrient. ${ }^{35}$ Although not considered an essential element, silicon is beneficial to plants by providing resistance against pests and pathogens, and by increasing the tolerance to toxic metals and drought, contributing to higher crop yields. ${ }^{36-38}$ In this sense, there are many available methods in the literature aiming at silicon determination in plant materials. ${ }^{39-44}$ However, most of them are labor-intensive, requiring several steps in the analytical sequence.

Regarding iron and phosphorus, there was an expectation to determine these analytes directly in fresh leaves, based on previous studies with dry leaves analyzed by benchtop EDXRF and LIBS. ${ }^{12}$ However, it was not possible to build calibration models, due to the lack of appropriate calibration test samples presenting $\mathrm{Fe}$ and $\mathrm{P}$ mass fractions above their corresponding limits of quantification. It is important to stress that the fitness of the calibration models depends on the availability of appropriate calibration test samples and on the inherent method sensitivity.

Once the feasibility of in situ quantitative determinations of nutrients and a beneficial element in such important agricultural crop was demonstrated, it is relevant to propose a measurement protocol with higher analytical throughput. In this particular case, the sampling strategy can contemplate the use of a portable sample holder composed of an x-y linear translation stage, where the middle-third portion of the fresh diagnostic leaf is fixed, and it moves continuously in front of the handheld EDXRF instrument. The movement of this sample holder can be synchronized in such a way that in the total measurement time $(50 \mathrm{~s})$, the entire leaf is scanned, and the obtained spectrum will represent the whole test sample.

Moreover, for expanding the detection power of the in situ method, the middle-third portion of the sugar cane diagnostic leaf can be dried in a microwave oven in less than 5 min. ${ }^{45}$ Once dried, $\mathrm{P}, \mathrm{Fe}$, and $\mathrm{Mn}$ can also be properly quantified in this test sample, as demonstrated elsewhere. ${ }^{12}$

Another point that deserves emphasis relates to the evaluation of different calibration strategies for obtaining accurate data. The analytical curve built with pellets of ground sugar cane leaves is very simple and proven to be useful for obtaining mass fraction data directly in the field, thus avoiding even the necessity of sample transportation to the laboratory. The fundamental parameters ${ }^{46}$ and the emission-transmission ${ }^{47}$ methods can also be evaluated for the quantitative determination of the target analytes, and these calibration approaches can be used together for cross-checking. Finally, it is important to be aware about recent developments for plant mineral analysis by alternative and/or complementary spectroscopic methods, particularly those to detect element latent deficiencies. ${ }^{1,48}$

Table 1. Analytical figures of merit, critical levels and optimal ranges for the target analytes

\begin{tabular}{|c|c|c|c|c|c|c|}
\hline $\begin{array}{l}\text { Analyte } \\
\text { (X-ray energy) }\end{array}$ & $\begin{array}{l}\mathrm{LOD}^{\mathrm{a}} / \\
\left(\mathrm{g} \mathrm{kg}^{-1}\right)\end{array}$ & $\begin{array}{c}\mathrm{RMSEP}^{\mathrm{a}} / \\
\left(\mathrm{g} \mathrm{kg}^{-1}\right)\end{array}$ & $\begin{array}{l}\mathrm{LOD}^{\mathrm{b}} / \\
\left(\mathrm{g} \mathrm{kg}^{-1}\right)\end{array}$ & $\begin{array}{c}\mathrm{RMSEP}^{\mathrm{b}} / \\
\left(\mathrm{g} \mathrm{kg}^{-1}\right)\end{array}$ & $\begin{array}{l}\text { Critical levelc / } \\
\left(\mathrm{g} \mathrm{kg}^{-1}\right)\end{array}$ & $\begin{array}{c}\text { Optimal range } / \\
\left(\mathrm{g} \mathrm{kg}^{-1}\right)\end{array}$ \\
\hline $\mathrm{Si}(\mathrm{K} \alpha 1.74 \mathrm{keV})$ & 0.35 & 0.75 & 0.50 & 0.36 & 5 & $\geq 6$ \\
\hline $\mathrm{S}(\mathrm{K} \alpha 2.31 \mathrm{keV})$ & 0.51 & 0.10 & 0.13 & 0.04 & 1.3 & $1.3-1.8$ \\
\hline $\mathrm{K}(\mathrm{K} \alpha 3.31 \mathrm{keV})$ & 0.48 & 1.06 & 0.09 & 0.70 & 9 & $10-16$ \\
\hline $\mathrm{Ca}(\mathrm{K} \alpha 3.69 \mathrm{keV})$ & 0.24 & 0.39 & 0.06 & 0.16 & 2.0 & $2.0-4.5$ \\
\hline
\end{tabular}

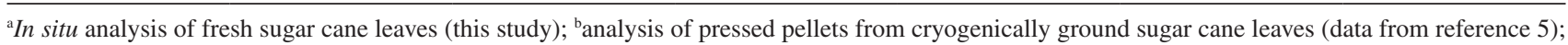
${ }^{c}$ critical levels and optimal ranges for $\mathrm{Si}, \mathrm{S}, \mathrm{K}$ and $\mathrm{Ca}$ in the sugar cane crop (data from reference 34). LOD: limit of detection; RMSEP: root mean square error of prediction. 


\section{Conclusions}

The proposed in situ method of analysis allowed a rapid evaluation of the nutritional profile of sugar cane plants avoiding the time-consuming sample preparation steps, namely drying, grinding, weighing and acid digestion.

Of particular interest is the attainment of accurate data in real time for nutrients $(\mathrm{K}, \mathrm{Ca}$, and $\mathrm{S})$ and a beneficial element ( $\mathrm{Si}$ ) from the in situ analysis of fresh sugar cane leaves. Manganese can also be determined, but validation still requires more robust calibration models. This method is a powerful analytical tool, especially for the precision agriculture practitioners contributing to the higher yields of sugar cane, an important cash crop of the tropical regions.

Another significant outspread of the proposed handheld EDXRF method is the possibility of conducting in vivo quantitative analysis of plants in laboratory conditions providing a fast response in physiological and kinetic studies.

\section{Supplementary Information}

Supplementary information (Figure S1) is available free of charge at http://jbcs.sbq.org.br as PDF file.

\section{Acknowledgments}

The authors are grateful to FAPESP (2012/16203-5), CNPq (309679/2014-1, 141034/2016-5), CAPES, and NSF (MRI Award 1429544) for financial support and grants. Dr Paulino Souza is also thanked for sampling help at the Centro de Tecnologia Canavieira. We also express our gratitude to MSc Clauber Bonalume and Mr Wilson Hernandes (Anacom Científica) for technical support, and to Dr Brianna Mount for language improvement.

\section{References}

1. van Maarschalkerweerd, M.; Husted, S.; Front. Plant Sci. 2015, 6, ID 169, DOI 10.3389/fpls.2015.00169.

2. Barnes, R. M.; Santos Jr., D.; Krug, F. J. In Microwave-Assisted Sample Preparation for Trace Element Determination; Flores, E. M. M., ed.; Elsevier: Amsterdam, Netherlands, 2014, ch. 1.

3. Marguí, E.; Queralt, I.; Hidalgo, M.; Trends Anal. Chem. 2009, 28,362 .

4. Tezotto, T.; Favarin, J. L.; Paula Neto, A.; Gratão, P. L.; Azevedo, R. A.; Mazzafera, P.; Sci. Agric. 2013, 70, 263.

5. Guerra, M. B. B.; Almeida, E.; Carvalho, G. G. A.; Souza, P. F.; Nunes, L. C.; Santos Jr., D.; Krug, F. J.; J. Anal. At. Spectrom. 2014, 29, 1667.
6. Santos Jr., D.; Nunes, L. C.; Carvalho, G. G. A.; Gomes, M. S.; Souza, P. F.; Leme, F. O.; Santos, L. G. C.; Krug, F. J.; Spectrochim. Acta, Part B 2012, 71-72, 3.

7. Tripathi, D. K.; Pathak, A. K.; Chauhan, D. K.; Dubey, N. K.; Rai, A. K.; Prasad, R.; Biocatal. Agric. Biotechnol. 2015, 4, 471.

8. Carvalho, G. G. A.; Moros, J.; Santos Jr., D.; Krug, F. J.; Laserna, J. J.; Anal. Chim. Acta 2015, 876, 26.

9. Cizdziel, J.; Bu, K.; Nowinski, P.; Anal. Methods 2012, 4, 564.

10. Oliveira, S. R.; Arruda, M. A. Z.; J. Anal. At. Spectrom. 2015, $30,389$.

11. Nunes, M. A. G.; Voss, M.; Corazza, G.; Flores, E. M. M.; Dressler, V. L.; Anal. Chim. Acta 2016, 905, 51.

12. Guerra, M. B. B.; Adame, A.; Almeida, E.; Carvalho, G. G. A.; Brasil, M. A. S.; Santos Jr., D.; Krug, F. J.; J. Anal. At. Spectrom. 2015, 30, 1646.

13. Gałuszka, A.; Migaszewski, Z. M.; Namieśnik, J.; Environ. Res. 2015, 140, 593.

14. Rakovský, J.; Čermák, P.; Musset, O.; Veis, P.; Spectrochim. Acta, Part B 2014, 101, 269.

15. Melquiades, F. L.; Appoloni, C. R.; J. Radioanal. Nucl. Chem. 2004, 262, 533.

16. Carr, R.; Zhang, C.; Moles, N.; Harder, M.; Environ. Geochem. Health 2008, 30, 45.

17. Shuttleworth, E. L.; Evans, M. G.; Hutchinson, S. M.; Rothwell, J. J.; Water, Air, Soil Pollut. 2014, 225, 1.

18. Fortes, F. J.; Laserna, J. J.; Spectrochim. Acta, Part B 2010, 65, 975.

19. Barbafieri, M.; Pini, R.; Ciucci, A.; Tassi, E.; Chem. Ecol. 2011, $27,161$.

20. West, M.; Ellis, A. T.; Potts, P. J.; Streli, C.; Vanhoof, C.; Wobrauschek, P.; J. Anal. At. Spectrom. 2015, 30, 1839.

21. Cuñat, J.; Palanco, S.; Carrasco, F.; Simón, M. D.; Laserna, J. J.; J. Anal. At. Spectrom. 2005, 20, 295.

22. Quye-Sawyer, J.; Vandeginste, V.; Johnston, K. J.; J. Anal. At. Spectrom. 2015, 30, 1490.

23. Frahm, E.; Doonan, R. C. P.; J. Archaeol. Sci. 2013, 40, 1425.

24. Spizzichino, V.; Fantoni, R.; Spectrochim. Acta, Part B 2014, 99, 201.

25. Bosco, G. L.; Trends Anal. Chem. 2013, 45, 121.

26. Weindorf, D. C.; Bakr, N.; Zhu, Y.; Adv. Agron. 2014, $128,1$.

27. Tighe, M.; Forster, N.; Commun. Soil Sci. Plant Anal. 2014, 45, 53.

28. Reidinger, S.; Ramsey, M. H.; Hartley, S. E.; New Phytol. 2012, 195, 699 .

29. McLaren, T. I.; Guppy, C. N.; Tighe, M. K.; Soil Sci. Soc. Am. J. 2012, 76, 1446.

30. Towett, E. K.; Shepherd, K. D.; Lee Drake, B.; X-Ray Spectrom. 2016, 45, 117.

31. Dao, T. H.; Comput. Electron. Agr. 2016, 129, 84.

32. Currie, L. A.; Pure Appl. Chem. 1995, 67, 1699. 
33. Currie, H. A.; Perry, C. C.; Ann. Bot. 2007, 100, 1383.

34. McCray, J. M.; Rice, R. W.; Ezenwa, I. V.; Lang, T. A.; Baucum, L. In Florida Sugarcane Handbook; Rice, R. W., ed.; Institute of Food and Agricultural Sciences: Gainsville, FL, USA, 2013, SS-AGR-128.

35. Savant, N. K.; Korndörfer, G. H.; Datnoff, L. E.; Snyder, G. H.; J. Plant Nutr. 1999, 22, 1853.

36. Hartley, S. E.; Fitt, R. N.; McLarnon, E. L.; Wade, R. N.; Front. Plant Sci. 2015, 6, 1.

37. Raven, J. A.; New Phytol. 2003, 158, 419.

38. Richmond, K. E.; Sussman, M.; Curr. Opin. Plant Biol. 2003, $6,268$.

39. van der Vorm, P. D. J.; Commun. Soil Sci. Plant Anal. 1987, 18, 1181.

40. Novozamsky, I.; van Eck, R.; Houba, V. J. G.; Commun. Soil Sci. Plant Anal. 1984, 15, 205.

41. Guntzer, F.; Keller, C.; Meunier, J. D.; New Phytol. 2010, 188, 902.

42. Elliott, C. L.; Snyder, G. H.; J. Agric. Food Chem. 1991, 39, 1118 .
43. Kraska, J. E.; Breitenbeck, G. A.; Commun. Soil Sci. Plant Anal. 2010, 41, 2075.

44. Beine, R. L.; AOAC Official Method 920.08 - Sand and Silica in Plants. Gravimetric Method; Association of Official Analytical Chemists: Rockville, USA, 2011.

45. Marur, C. J.; Sodek, L.; Rev. Bras. Fisiol. Veg. 1995, 7, 111.

46. Omote, J.; Kohno, H.; Toda, K.; Anal. Chim. Acta 1995, 307, 117.

47. Blonski, M. S.; Appoloni, C. R.; Parreira, P. S.; Aragão, P. H. A.; Nascimento Filho, V. F.; Braz. Arch. Biol. Technol. 2007, 50, 851 .

48. Frydenvang, J.; van Maarschalkerweerd, M.; Carstensen, A.; Mundus, S.; Schmidt, S. B.; Pedas, P. R.; Laursen, K. H.; Schjoerring, J. K.; Husted, S.; Plant Physiol. 2015, 169, 353.

Submitted: September 4, 2017 Published online: December 13, 2017 